\title{
Los agentes del estado y los comportamientos punibles de comisión por omisión*
}

\author{
The state agents and the punishable commission behaviors of omissiono método \\ Singapura: reflexão sobre o processo de ensino - aprendizagem das matemáticas
}

DOI: https://doi.org/10.21803/pensam.v12i22.258

Mariela Vargas Prentt

https://orcid.org/0000-0001-5970-4860

\begin{abstract}
Resumen
En este artículo de reflexión, es apropiado examinar las razones que sustentan la posición de garante de los Agentes del Estado en consideración a sus posibles conductas omisivas que devienen en resultados típicos que lesionan o ponen en peligro los bienes jurídicos tutelados. Lo expresado si se tiene en cuenta que quien omite tiene que responder por el resultado que produzca, lo que de por sí es algo de gran complejidad y aún más, cuando quien lo hace forma parte del andamiaje estatal. El asunto no sólo tiene una dimensión teórica-estatal, sino una medida de mayor profundidad cuya aclaración es necesaria para poder definir el problema de la garantía que surge de un deber "funcional" que puede estar previsto en la ley o se puede deducir de ella.
\end{abstract}

El sustraerse el servidor público del deber, se traduce en daño a una persona o grupo de personas y ese mismo detrimento, en determinadas circunstancias, conllevaría a una posible conducta de omisión impropia con la punición que ella amerita. Ello surge de las relaciones existentes entre el Estado y los ciudadanos; problemática que por sí no se puede resolver mediante una simple interpretación legal, sino que abarca la exposición de basilares reflexiones jurídicas, sociojurídicas y desde luego, argumentativas.

Palabras Clave: Agentes del Estado; conducta punible; comisión por omisión; posición de garante; bien jurídico tutelado.

\begin{abstract}
In this article of reflection, it is appropriate to examine the reasons that support the position of guarantor of State Agents in consideration of their possible omissive behaviours that result in typical injure or endanger legally protected assets. The expressed if it is taken into account that the one who omits has to answer for the result that it produces, which in itself is something of high complexity and even more, when who does it is part of the state scaffolding. The matter not only has a theoretical-state dimension but a measure of greater depth whose clarification is necessary to be able to define the problem of the guarantee that arises from a "functional" duty that can be provided for in the law or can be deduced from it.

Subtracting the public servant from duty, translates into damage to a person or group of people and that same detriment, in certain circumstances, would lead to a possible improper omission behaviour with the punishment it deserves. This issue arises from the existing relations between the State and citizens; problematic that by itself cannot be solved by a simple legal interpretation, but covers the exposition of basilar legal, socio-legal and, of course, argumentative reflections.
\end{abstract}

Key words: State agents; punishable conduct; default commission; guarantor position; legal good protected. 


\section{Resumen}

Neste artigo de reflexão, é apropriado examinar as razões que apoiam a posição de sujeito garantista dos agentes do Estado em consideração a seus possíveis comportamentos omissos que resultam em resultados que prejudicam ou expõem ao perigo os ativos legais protegidos. Se toma em conta que aquele que omite tem que responder pelo resultado que produz, o que em si é algo complexo, ainda mais quando quem faz parte dessa manobra pertence ao andaime do Estado. $O$ assunto não só tem uma dimensão teórico-estatal, mas uma medida de maior profundidade cuja clarificação é necessária para poder definir o problema da garantia que surge de um dever "funcional" que pode ser previsto na lei ou que pode ser deduzido a partir dela.

Subtrair o servidor público do dever traduz-se em danos a uma pessoa ou grupo de pessoas e esse mesmo prejuízo, em certas circunstâncias, levaria a um possível comportamento inadequado de omissão com a punição que essa pessoa merece. Isso decorre das relações existentes entre o Estado e os cidadãos; problemática que por si só não pode ser resolvida por uma simples interpretação jurídica, mas abrange a exposição de reflexões legais, sócio-legais e, obviamente, argumentativas.

Palavras-chave: agentes do Estado; conduta punível; comissão padrão; sujeito garantista; bem legal protegido.

\section{Perfil}

Docente de Carrera e Investigadora de la Facultad de Ciencias Jurídicas de la Universidad del Atlántico, grupo INVIUS. Máster en Argumentación Jurídica de la Universidad de Alicante (España); Master di II livello in Argomentazione Giuridica de la Università di Palermo (Italia). marielavargasprentt3@msn.com.

\section{Mariela Vargas Prentt}

Especialista en Derecho Penal y Criminologia de la Universidad Libre (Colombia) 


\section{Introducción}

La expresión "Agentes del Estado", tiene un significado polisémico. En tal sentido, se le asocia con servidor público, funcionario público, empleado público, trabajador oficial, entre otros.

En este orden de ideas, para efectos de la siguiente investigación sociojurídica, cuando se refiera a la expresión "Agentes del Estado", su alcance se circunscribirá a lo plasmado en el artículo 20 del Código Penal colombiano ${ }^{1}$

Después de lo expresado, conviene dilucidar lo relacionado con la posición de garante; asunto que sitúa el debate entre los tratadistas y teóricos al referirse a los delitos de comisión por omisión. No obstante, se tratará de determinar cuáles son los fundamentos que llevan a la conversión de los Agentes del Estado -y al mismo Estado-, en garantes. En ese sentido -y asumiéndose una posición crítica y reflexiva de la cuestión-, se requiere incluir en este asunto un espacio que distinga entre los deberes morales y sociales comunes a todo ciudadano, y los deberes especiales de protección, a fin de precisar por medio de la dogmática jurídica, la responsabilidad de los Agentes del Estado.

Lo anterior, siempre y cuando se vincule a los servidores del Estado como sujetos activos de un comportamiento punible de comisión por omisión frente a un deber jurídico de impedir un resultado perteneciente a una descripción típica y no lo llevare a cabo, estando en posibilidad de hacerlo, quedará sujeto a la pena contemplada en la referida norma penal. Para tal efecto, se requiere que el agente tenga a su cargo la protección en concreto del bien jurídico protegido o que se la haya encomendado como garante la vigilancia de una determinada fuente de riesgo, conforme a la Constitución o la ley, tal y como lo consagra el artículo 25 del Código Penal colombiano. Esto es, que sean titulares de un deber jurídico especial que les compele a responder por la no evitación del resultado, encontrándose en la posibilidad de poder realizarlo.

Finalmente, conviene exaltar que, atender el tema del origen de la posición de garante o de garantía, responde a la necesidad de estimar los basamentos de la dogmática jurídica, es decir, que debido a la compleja estructura sistémica en la esfera jurídica, es apropiado hacer una somera revisión de las fuentes (formales y materiales) de la posición de garantía, teniendo en cuenta que para entender de dónde dimana el deber de actuar positivamente, amerita una sana revisión del asunto.

\section{Resultados y Discusión}

\section{Punto de partida del estudio de la posición de garante de los Agentes del Estado}

Previo a la fijación propia del artículo dentro del marco del debate, es necesario hacer una serie de precisiones relacionadas con el significado, que de ahora en adelante se le dará a algunas expresiones lingüísticas que se emplearán durante su desarrollo.

Del mismo modo, se examinarán las razones que sustentan la posición de garante de los Agentes del Estado en consideración a sus posibles conductas omisivas que devienen en resultados típicos que dañen, lesionen o pongan en peligro bienes jurídicos tutelados por el Estado.

Lo expresado si se tiene en cuenta que quien omite tiene que responder por el resultado

1 Dicho artículo consagra lo siguiente: "Artículo 20. Servidores públicos. Para todos los efectos de la ley penal, son servidores públicos los miembros de las corporaciones públicas, los empleados y trabajadores del Estado y de sus entidades descentralizadas territorialmente y por servicios. Para los mismos efectos se consideran servidores públicos los miembros de la fuerza pública, los particulares que ejerzan funciones públicas en forma permanente o transitoria, los funcionarios y trabajadores del Banco de la República, los integrantes de la Comisión Nacional Ciudadana para la Lucha contra la Corrupción y las personas que administren los recursos de que trata el artículo 338 de la Constitución Política."

Pensamiento Americano Vol. 12 - No. 23 • 2019 • Enero - Junio · Corporación Universitaria Americana • Barranquilla, Colombia • ISSN: $2027-2448$. http://publicaciones.americana.edu.co/index.php/pensamientoamericano/index 
que produzca, lo que de por sí es algo de gran complejidad, y aún más, cuando quien lo hace forma parte del andamiaje estatal.

Se debe precisar, como ya se afirmó, que es el Estado quien crea el Derecho abordado en su sentido amplio y por tanto, ello no se limita a la expedición de la legislación del caso, sino que se traduce en el conjunto de actividades que conforman un Estado de Derecho. De tal manera, que quien actúa desde esta órbita se encuentra frente a una relación distinta a la existente entre particulares.

Por ello, la cuestión no solo tiene una dimensión teórica-estatal, sino una medida de mayor profundidad cuya aclaración es necesaria para poder definir el problema de la garantía que surge de un deber "funcional" que puede estar previsto en la ley o se puede deducir de ella, produciéndose por tanto, el reforzamiento de la posición jurídica del individuo que lo representa. Ello permite afirmar que el hecho de que el servidor público se sustraiga a su deber jurídico, produce un daño a una persona o grupo de personas; ese mismo daño, en determinadas circunstancias, conllevaría a una posible conducta de comisión por omisión con la correspondiente secuela punitiva.

Como se ha expresado de las relaciones existentes entre los servidores públicos y los particulares pueden resultar comportamientos punibles de omisión impropia con la aparejada problemática que ello conlleva, no solo desde la órbita del Derecho Penal, sino que acarrea un asunto de interpretación de leyes, que además, abarca como se estimó en la parte introductoria de este artículo, la exposición de basilares reflexiones jurídicas, sociojurídicas $\mathrm{y}$, desde luego argumentativas.

\section{Alcance de la expresión "Agentes del Estado"}

Se aclaró que ésta expresión es de carácter polisémico, por lo que se asocia con otros conceptos como empleado público, funcionario público, servidor público, entre otros, y para efectos de esta investigación será oportuno acogerse al marco conceptual que el artículo 20 del Código Penal colombiano consagra.

\section{Posición de garante de los Agentes del Es- tado}

La posición de garante en los delitos de comisión por omisión, es una temática que nunca ha sido pacífica, pero por el momento se tratará de determinar cuáles son los fundamentos que lleven a la conversión de los Agentes del Estado -y al mismo Estado-, en garantes; por ello pueden incurrir en delitos de comisión por omisión y en consecuencia, dar lugar a responsabilidad penalmente relevante, en virtud de la imputación de un resultado a quien tenía el deber jurídico de evitarlo.

En términos generales, se podría decir que la cercanía de una persona con un bien jurídico puede generarle el deber de actuar o de intervenir para salvaguardarlos o protegerlos contra una determinada fuente de riesgo, de manera que lo característico de los punibles de comisión por omisión es el deber jurídico de actuar para evitar un resultado lesivo a un bien jurídico, asunto conocido en el ámbito jurídico penal como "deber de salvamento o de evitar el resultado".

Los llamados deberes especiales de intervención a través de un actuar para salvaguardar determinados bienes jurídicos, se les identifica como deberes de garantía, y a sus titulares se les conoce como garantes. Tales deberes especiales, no deben confundirse con los simples deberes sociales o morales, porque ello podría atentar contra el Principio de Legalidad. Esta clase de deberes sociales de carácter general y amplio, dimanan del respeto por el otro y del Principio de Solidaridad, y se traducen en de- 
beres jurídicos específicos y por consiguiente, no convierte a las personas en general en garantes de los demás.

En otras palabras, no cualquier deber social o moral, tiene la virtud de convertir a una persona en garante de otra por la no evitación de ciertos resultados que afecten a un bien jurídico del cual es titular.

Al inicio del Estado Liberal Individualista o Estado Gendarme, se pretendía imponer cargas excesivas a los ciudadanos, lo que era censurable, pues el Estado perseguía descargarse de sus obligaciones e imponérselas a los coasociados, de ahí la aprehensión con la que eran apreciadas las conductas omisivas penalmente relevantes.

Como es fácil comprender, el concepto jurídico de omisión tenía y tiene escasa cabida en esas concepciones, salvo en casos excepcionales relativo a las mínimas obligaciones que se imponen al individuo hacia el poder Estatal, o en relación con él, y a obligaciones éticas, de tal manera apremiantes que se las eleva a la condición de exigencias ineludibles de la vida social (Conviene recordar que se trata de regímenes que se han denominado en sí mismos como occidentales y cristianos.)...

...Esas concepciones ideológicas, originaron una reacción de parte de quienes aprecian en ellas la ausencia de un contrapeso capaz de equilibrar las ideas de libertad e igualdad, predicadas por ellas, con una realidad social de desigualdades -particularmente económicas- cada vez mayores, que afectaba necesariamente a la libertad proclamada. Se criticó la idea de una sociedad atomizada en miembros autónomos y se postuló el deber de todo hombre de preocuparse de sus semejantes, no tan sólo por razones éticas, sino también por obligación jurídica emanada de un sistema de organización social que ha de estar basado en la solidaridad (correspondiente, en parte, a aquella "fraternidad" pregonada por la Revolución Francesa, pero olvidada como realización por sus seguidores (Novoa Monreal, 1984).

En cuanto a lo reseñado se debe aclarar que el Estado no debe despojarse de sus obligaciones y encomendarlas a las personas coasociadas, sobre todo bajo la amenaza de la sanción penal, convirtiéndose de alguna manera al Derecho Penal de prima ratio bajo la etiqueta de la solidaridad, olvidándose de cierto modo, de sus propios fines.

Otro asunto sería bajo el "muro de contención" del pluralismo ideológico de los Estados democráticos que limitó el incremento, de cierto modo desmedido, de las conductas omisivas, donde la persona era sojuzgada por el Estado para la obtención de sus fines, y donde se buscaba hacer de cada ciudadano un funcionario.

Con la revisión suscitada y el surgimiento de las normas jurídicas de mandato, se facilitó su comprensión, no sólo desde lo que le compete a los que representan al Estado sino muy comedidamente a las personas en particular. En tal sentido, los servidores públicos pasaron a cumplir sus verdaderos roles dentro del andamiaje estatal, al ser considerados garantes en el ejercicio de sus funciones.

Expresado en otros términos, los Agentes del Estado poseen un "status" especial, y como tal, deben procurar por el interés general y la protección de ciertos bienes jurídicos que le han sido asignados dadas sus particulares funciones. Por tanto, si un Agente del Estado que ostenta la posición de garante, no evita un resultado que dañe, lesione o ponga en riesgo o 
peligro un bien jurídico tutelado, puede estar inmerso en un delito de comisión por omisión, y por ende puede acarrearle, según el caso, responsabilidad penal.

En este sentido, se ha afirmado que la posición de garante de los Agentes del Estado, no implica un deber amplio de protección o salvaguarda ante situaciones que dañen, lesionen o pongan en peligro al individuo y sus más importantes derechos fundamentales; sin embargo, la opinión dominante en la doctrina y en la jurisprudencia -especialmente la alemana- es de otro parecer; vale decir, que se trata de una órbita restringida de deberes jurídicos que los vinculan más o menos directamente o de manera cercana o próxima con ciertos bienes jurídicos de los que son titulares los administrados.

Asimismo, se discute sobre lo que se entiende como garante con función de protección y garante con función de vigilancia, particularmente, para diferenciar el uno del otro.

A propósito de la doctrina alemana, no se puede perder de vista el papel jugado por Günther Jakobs (2000) en lo que respecta a los delitos de comisión por omisión y la posición de garante de algunas personas en particular y en especial de los servidores del Estado; pues como es sabido, el jurista alemán fue impactado en sus reflexiones por Hegel, respecto de lo que se entiende como libertad y voluntad, desde el ámbito de la imputación objetiva.

Jakobs (2000, 92), resume que existen competencias por instituciones y que las personas viven en un mundo socialmente establecido, surgiendo al efecto derechos y deberes entre ellas, y por lo mismo, la responsabilidad penal aflora por el incumplimiento o inobservancia de esas pautas entre los particulares y en el eventual caso de los representantes del Estado frente a las exigencias o requerimientos de los coasociados. En punto de lo sostenido por el citado filósofo del Derecho en las Instituciones Estatales en las que interactúan los servidores del Estado, surgen deberes positivos que se materializan en proporcionar ayuda a las personas, mediante los llamados "deberes de confianza especial o de la función pública".

Por tanto, dichas reglas o pautas no pueden ser desconocidas o lesionadas, porque de ello devienen las consecuencias de los correspondientes tipos penales, generándose ante eso, el deber de actuar, que en contexto implica a su vez, el deber de actuar de los Agentes del Estado, so pena de la consecuente represión punitiva.

Dicho de otro modo, el deber de actuar, apunta a la existencia de deberes que competen a todos, lo que engloba al ciudadano del común $\mathrm{y}$ a las personas que fungen con un fuero o "status" especial, lo que conlleva a los conocidos delitos de infracción de deber. Se reitera que lo anterior es predicable de los servidores públicos, quienes ostentan un rol especial en el tejido social que debe propender por el interés general y de la tutela de los bienes jurídicos más importantes, dado sus especiales funciones oficiales.

De acuerdo con lo plasmado, se debe recordar que:

...la posibilidad de la comisión de un delito mediante la omisión de un funcionario plantea dificultades adicionales, pues para ello se deben cumplir los requisitos especiales que se exigen para la relevancia jurídica del omitir. El fundamento jurídico que posibilita elevar la no-realización de una acción a la condición de comportamiento jurídicamente relevante es la posición de garante. Ésta consiste en una relación de proximidad, fundamentada por su parte por determinados 
elementos, que existe entre el omitente y aquel a quien le amenaza una lesión, bien por la naturaleza, bien por otras personas. La afirmación de la posición de garante de una persona significa que en casos de peligro, el amenazado por este último puede confiar en la intervención del garante con tanta seguridad que la omisión de la intervención equivale a un comportamiento activo de lesión. El fundamento de esta relación de proximidad es personal -preestatal y se encuentra en el ámbito del actuar jurídico- responsable del individuo mismo. La exigencia de tales deberes jurídicos como presupuesto de la punibilidad del omitente es una consecuencia del hecho de que en derecho no se puede-por así decirlo- hacer trabajar a cualquier otro por la conservación del propio círculo jurídico. Una posición de garante solamente está fundamentada cuando se puede afirmar que existe una verdadera dependencia del actuar del garante, de tal manera que su actuar se puede tener en cuenta como seguro en la puesta en práctica de la vida. En tal caso, también existe una pretensión jurídica a su actividad y el individuo no está solo en su necesidad, sino que puede confiar en el actuar del otro (Zaczyk, 2010).

Sin duda, los servidores públicos constituyen parte fundamental de la competencia institucional del Estado; además, por su proximidad con el ordenamiento jurídico podría decirse que se abrogan voluntariamente la posición de garantes. Esto último, se traduce en que el Estado les impone obligaciones, o mejor expresado, deberes que los vinculan de manera directa con los coasociados que estén relacionados con su protección o que en un determinado momento, deba prestarles ayuda, protección o vigilancia.

Así, por ejemplo, el Código Único Disciplinario de Colombia, (Ley 734, 2002) en el Título IV, Capítulo Segundo y Tercero, consagra en términos generales los deberes y prohibiciones de los servidores públicos, e igualmente y de manera más amplia, se consagran en la Constitución y en la ley. Ahora bien, se debe destacar que una característica esencial del sujeto activo de los comportamiento punibles de comisión por omisión, estriba precisamente en que éste está obligado a hacer algo en favor de una persona que a su vez se encuentra en capacidad de exigir esa actividad, en virtud de un dispositivo coercitivo que le permita asegurar el cumplimiento de lo debido, y más aun tratándose de los servidores públicos.

De tal manera que el Estado criminaliza la pasividad de quien por la Constitución o la ley tenga la obligación de actuar a favor de un tercero, pues además, la sociedad tiene la expectativa o la aspiración de que tal obligación sea satisfecha; vale decir, que ese sujeto tenga el deber de garantizar la indemnidad del bien jurídico del caso.

En lo que particularmente atañe a los servidores del Estado para que éstos sean considerados agentes de un comportamiento punible de comisión por omisión y, consecuentemente, ser penalizados, se requiere que jurídicamente estén obligados a la evitación del resultado; o sea, que sean titulares de un especial deber jurídico que les compele a responder por la no evitación del resultado.

De tal manera, que no bastará acreditar la existencia de un deber jurídico especial sumado a la posición de garante, sino que además, es indispensable comprobar el elemento subjetivo del comportamiento, o sea, el dolo o la culpa en el proceder, en el entendido que el Estado por conducto de los servidores públicos, busca la tutela y protección de los derechos de las personas. 
Sobre la base de lo expresado y admitida la condición de la existencia del Estado, se discute el grado de garantía con que puedan contar los coasociados y de su efectiva y eficaz tutela y protección.

Los agentes del Estado en tales circunstancias, se encuentran enmarcados en una posición de garante, pero desde un sentido restringido. Sobre lo recién afirmado, es menester aclarar que la posición de garante puede interpretarse en un sentido amplio o general y en un sentido estricto o lato; lo que puede pregonarse según sea la especial -o no- relación del sujeto con el bien jurídico.

De acuerdo con lo anterior, resulta pertinente aclarar que la especial vinculación del agente o autor con el bien jurídico o con su titular, da lugar al deber jurídico de evitar el resultado y en consecuencia, a la posición de garante. Se trata de un sujeto activo calificado que está investido de una especial obligación jurídica de proteger un determinado bien jurídico o resguardar su integridad, y por ello, debe evitar lesionarlo, e igualmente actuar de forma positiva dentro de sus posibilidades para impedir los riesgos, peligros o amenazas a los que pueda estar expuesto o sometido en un momento determinado.

Se reitera, se trata de deberes jurídicos y no de deberes morales o sociales de solidaridad y que frente a los agentes del Estado, seguramente se acentuará tal caracterización. Sobre esta base, se evidencia fácilmente la diferencia entre deber jurídico, deber moral y deber ético, se reafirma se trata de deberes jurídicos de los servidores públicos frente a los bienes jurídicos de los coasociados.

El deber jurídico deviene en vinculante para el agente, pues se encuentra establecido en la normativa jurídica; en cambio el deber moral dimana de la moral o de los usos sociales.
De tal manera que el punto de partida que los diferencia es el origen de su obligación. En este orden, el deber jurídico presupone la existencia ex antes de una norma jurídica que lo prevé, como requisito de realizar una conducta o como prohibición de realizarla. En consecuencia, en virtud del carácter coercitivo del Derecho, su cumplimiento puede ser exigido mediante la amenaza de una sanción penal o disciplinaria, según el caso.

Expresado de otra manera, el deber jurídico posibilita la aplicación de una sanción en la eventualidad de su incumplimiento; en cambio, el deber moral conlleva a que el sujeto vinculado con él, conozca su contenido, esté o no de acuerdo con él y por ende puede o no aceptarlo.

Recapitulando, la posición de garante de los agentes del Estado se relaciona con el concepto de autoridad pública e igualmente, con la circunstancia de formar parte de una Institución fundamentada en el servicio público, con el propósito de mantener la seguridad del territorio y de la protección o salvaguarda de los derechos fundamentales de sus coasociados.

Está claro que el Estado no responde penal o disciplinariamente por los comportamientos de sus agentes (llámense de acción, omisión propia o de comisión por omisión); aquél, a través del legislador, diseña mediante su poder de selección o de criminalización, instrumentos jurídicos encaminados a llevar a dichos campos de responsabilidad al servidor público, que funja en la posición de garante.

Asunto diferente sería que los agentes del Estado como sujetos activos de delitos de omisión impropia, tuvieran la responsabilidad de hacer lo posible de evitar las consecuencias lesivas a bienes jurídicos de terceros, no sólo al amparo de lineamientos normativos, sino también por el comportamiento ético y moral 
que debe caracterizar a sus representantes en el desarrollo de sus funciones.

El comportamiento de todo servidor público, no sólo debe vislumbrar el deber jurídico que lo obliga o lo vincula con los administrados, sino asimismo debe reflejar un sesgo en su actuar, en su aptitud of icial, ello en virtud de los valores éticos y morales que le impone la Constitución y la ley.

Ahora bien, no únicamente es posible -como se acreditará más adelante-, que se sancione dinerariamente al Estado por razones de indemnización por fallas en el servicio mediante la acción de reparación directa que interpone un ciudadano en contra del Estado, sino que también pueden derivarse sanciones al Estado desde el ámbito internacional, ampliando así su cobertura sancionatoria a un plano extranacional. En palabras de Jiménez García (2011), el tema es tratado así:

...calificando su posición como complicidad en la comisión del ilícito o, en su caso y de forma más apropiada, como supuesto de comisión por omisión...

A tal efecto se ha reconocido que la omisión, cuando existe un deber jurídico de actuar, puede comprometer la responsabilidad penal individual. Por otro lado, se ha concretado que el elemento material de la complicidad en la ayuda, asistencia o apoyo moral práctico que tenga un efecto importante en la perpetración del crimen -ayuda o asistencia que puede tener lugar antes, durante o después de la comisión principal- mientras que el elemento moral necesario implica el hecho de conocer que estos actos ayudan o asisten a la comisión del crimen. Este elemento material de la complicidad no necesariamente tiene que adoptar una forma positiva de acción, sino que puede consistir en una omisión a condición que la misma haya tenido un <<efecto sustancial >> en la perpetración del crimen cometido... (p. 35).

En el ámbito del Derecho Internacional de los Derechos Humanos, también se ha destacado la complicidad del Estado en determinados supuestos de omisión.

En ese mismo orden de ideas, "mutatis mutandi", surge la responsabilidad de los agentes del Estado, aparejándose con ello no solamente la posición de garante institucional, sino también el deber jurídico y moral de evitación del resultado lesivo a bienes jurídicamente tutelados. De tal manera que el rol de los servidores públicos se diferencia del de los ciudadanos, porque el comportamiento punible de comisión por omisión se surtirá si no cumplen el mandato jurídico de realizar la acción exigida, de lo que debe inferirse la producción del resultado y de su capacidad individual de deber y poder actuar, y por ende, su responsabilidad penal.

Los agentes del Estado tienen la obligación de ayudar o de ser solidarios o de realizar o hacer determinadas prestaciones respecto a ciertas personas o determinados bienes jurídicos.

En este contexto, una de las lagunas que precisamente debe llenar la doctrina y la jurisprudencia es la relacionada con la identificación de las fuentes de donde debe surgir o dimanar la posición de garante o del deber de garantía. A modo de bosquejo genérico, se desarrollarán en el acápite siguiente, los puntos más controvertidos que sobre el tema se han producido.

\section{Fuentes de la posición de garantía}

El punto de partida para dilucidar sobre la denominada fuente del deber de garantía, es es- 
tablecer de dónde dimana el deber de actuar positivamente, por lo que es necesario remitirse a las apreciaciones de Marco Terragni (2010), quien citando a Feuerbach manifiesta:

...la explicación original, la de Feuerbach, hablaba de la necesidad de que exista un especial fundamento jurídico. Ello hace imprescindible fijar la atención en los dos adjetivos que califican el sustantivo fundamento.

Es especial, porque no se trata de la misma razón genérica, en función de la cual a toda persona le está prohibido producir el efecto a que se refiere el tipo penal. Siendo el deber especial, no se le exige una actuación positiva a cualquier individuo, sino a alguien que es identificado en orden a un vínculo determinado que lo une con el bien de que se trate, y al que el Derecho quiere proteger.

Y es jurídico porque constituye una exigencia que impone a la sociedad utilizando su aparato organizado de poder para imponerle reglas de conducta bajo coerción. Expresada la idea con otras palabras: no se trata de un compromiso moral, sino de un deber cuyo acatamiento sea amenaza de que se pondrán en movimiento los mecanismos estatales para castigar de alguna manea al infractor.

Como resulta obvio, cualquiera sea el supuesto de hecho con trascendencia al mundo jurídico, la persona sobre la que recae el compromiso de actuar, no tiene el deber de evitar el resultado, sino el deber de hacer lo que esté a su alcance para que él no acontezca. Lo prohibido, entonces, no es el resultado, sino no realizar, quien tiene el deber jurídico de emprenderla, la actuación necesaria y posi- ble para que no tenga lugar el efecto al que se refiere el tipo de la ley penal...

...El mismo Feuerbach identificó cuáles son los manantiales, de los cuales emana la obligación jurídica sin cuya consecuencia "no puede haber ningún criminal por omisión." Según él lo expuso son la Ley y el Contrato (p. 363).

Las citadas figuras fueron denominadas por la doctrina fuentes formales, adicionándoles al efecto otra más, la conducta precedente o peligrosa también conocida como injerencia.

Por otro lado, la doctrina internacional conforme a lo expresado por Armin Kaufmann (1980), anuncia las fuentes materiales, también conocidas como fuentes funcionales, relacionadas con la posición de garante de una persona en consideración a un determinado bien jurídico. Por tanto, se abordarán tales tópicos sin perjuicio de volver sobre el tema de los comportamientos punibles de comisión por omisión de los agentes del Estado y su relación con las mencionadas fuentes del deber jurídico de garantía.

\section{Fuentes formales}

Esta concepción teórica se ha estimado como el punto de partida del origen de las fuentes de la posición de garante, porque precisamente dirige su atención hacia el umbral de los deberes de evitación de resultados lesivos a bienes jurídicos. Sobre lo respectivo, Forero Ramírez (2005), manifiesta:

...Esta teoría constituye una posición doctrinal ya superada, que se apoya en el origen (formal) de los deberes jurídicos, seguida en su momento entre otros por Jiménez de Asúa, quien también la denominó teoría formal de las fuentes jurídicas o consideración genética. 
La teoría formal de estirpe causalista consideraba que los delitos impropios de omisión se fundaban en los siguientes pilares:

- Una acción esperada que se omite.

- La afectación de un bien jurídico.

- La relación de causalidad entre la acción omitida y la afectación del bien jurídico.

Así las cosas, la omisión se equiparará a la acción si se comprueba: a) la existencia de un deber jurídico de actuar (ley, contrato, hecho precedente) y b) la causalidad hipotética. Dentro de las fuentes "formales" del deber jurídico de evitar un resultado encontramos la ley, el contrato y la injerencia." (p. 63).

\section{- La injerencia}

Acorde con la estricta perspectiva de las fuentes formales de garantía, se podría afirmar que esta figura no debió incluirse como una forma o manifestación de las mismas. La injerencia, conducta precedente o hecho precedente como fuente de la posición de garante, ha sido muy controvertida.

La mayor dificultad de la acción precedente como fuente del deber de garantía personal, surge de la vulneración del Principio de Reserva; no obstante esto, no se puede desconocer o prescindir del todo de su origen legal, puesto que la injerencia es consagrada de manera implícita en algunas legislaciones penales como fuente especial de la posición de garante. Nuevamente Terragni (2010), trayendo a colación a Feuerbach y Roxin, expresa:

Feuerbach había agregado la idea de que la posición de garante se genera por la conducta activa precedente a la omisión. Muchos años después la doctrina sigue utilizando este criterio, con otra terminología. Así, Roxin sostiene que el actuar precedente es el presupuesto decisivo para fundamentar la existencia de la posición de garante, puesto que solamente aquel a quien se pueda imputar el peligro creado conforme a criterios jurídicos, tiene responsabilidad y, por lo mismo, el deber de evitar la transformación del peligro en lesión.

Roxin actualiza la idea de posición de garante por injerencia, fijándole los límites conforme a la moderna teoría de imputación objetiva, de manera tal que la imputación objetiva del actuar precedente es el presupuesto decisivo para una posición de garante, puesto que sólo a quien se le puede imputar, conforme a criterios jurídicos, el peligro creado, tiene el deber de evitar la transformación en lesión. Se trataría de una posición de garante por control.

En lo anterior hay una aproximación a las ideas, según las cuales toda persona está obligada a evitar lesiones a bienes jurídicos, cuando su conducta previa haya provocado el peligro de protección de ese resultado. Toda persona está llamada a actuar como garante y proteger a aquellos bienes jurídicos que resulten amenazados por una fuente de peligro abierta por ella misma. La injerencia no puede obligar a la protección de determinados bienes jurídicos frente a toda clase de peligros y la posición de garante sólo puede ser reconocida respecto de aquellas lesiones de bienes jurídicos que representen la realización del peligro creado por la acción previa. Se exige como presupuesto de punibilidad una lesión de un bien jurídico objetivamente imputable a la posición de protección o de evitación del peligro (Terragni, 2010, p. 374). 
Regresándose sobre la delimitación de las fuentes formales de la posición de garante o del deber de garantía, se pueden apreciar como muy precarias si se les confronta con las circunstancias, necesidades y soluciones suscitadas por los posibles comportamiento punibles de comisión por omisión; esto independientemente de la concepción teórica que se implemente, pues la inclinación -como se verá más adelante-, es la de acoger los criterios o fuentes materiales o funcionales soportados sobre la base de la relación personal con el bien jurídico o con la persona. De manera que el rol social acarrea para las personas el comportamiento de unas expectativas, convirtiéndose en consecuencia para sus titulares en normas objetivas de comportamientos, desplazándose el deber jurídico por el deber social.

Esta teoría se fundamenta principalmente en las relaciones fácticas que se sustenten entre las partes al momento de ejercer o cumplir sus respectivos roles sociales. Es decir, que a partir del presupuesto teórico que señala que a cada individuo o persona dentro del tejido social se le han asignado funciones específicas vinculantes con el conglomerado y con la esperanza que se van a lograr o cumplir, permite inferir que cada individuo en un momento dado, debe asumir su responsabilidad frente a las expectativas que generó en las demás personas y que no respetó o acató.

Esta teoría se presenta como un enfoque más reciente, fundamentándose en la implementación de criterios materiales en el estudio de la temática de la posición de garantía, acorde -como ya se expresó- con las funciones que deben cumplir los individuos en el marco de realidad social.

Para efecto de la doctrina denominada teoría de las fuentes materiales o funcionales, la posición de garante puede tener dos orígenes distintos. Por una parte, un deber de custodia de bienes jurídicos; vale decir, defenderlos $\mathrm{y}$, por otra parte, un deber de aseguramiento de una fuente de peligro; o sea, su vigilancia con el fin de evitar el daño o vulneración de bienes jurídicos que en un momento dado pueden resultar afectados.

Por tanto, como basamento de la punibilidad se requiere un daño o lesión a un bien jurídico tutelado por el Estado y un comportamiento objetivamente imputable a la posición de protección o de evitación del peligro.

Vale la pena recalcar que respecto a lo recién enunciado no puede desconocerse la génesis legal, directa y especial de la posición de garante pero sin caer en la estricta teoría formal del deber jurídico.

Si la posición de garante se apoya en la razón jurídica formal de su origen, falta todo criterio objetivo de delimitación, porque la razón jurídica no cabe inferir qué amplitud ha de trazarse en cada caso el círculo de personas que cabe gravar con un deber de garante y qué deberes pueden suponerse a las mismas...

...Esta doctrina funcional del garante, distingue dos grupos de posiciones de garante. A su tenor, de un lado garantes que han de cumplir una función protectora para ciertos bienes jurídicos. Los bienes jurídicos que se encuentran al cuidado de un garante deben ser defendidos contra todas las puestas en peligro y daños jurídicos -penalmente relevantes- (garantes de cuidado). En las posiciones de garante que generan un deber de protección para determinados bienes jurídicos en este sentido amplio se incluye, por lo pronto, la solidaridad natural en el matrimonio y la familia, que obliga sobre todo a los padres frente a los hijos que viven en la misma casa y dependen de ellos, a la defensa contra los peligros para su integridad corporal y su vida. Un subgrupo de posiciones de

Pensamiento Americano Vol. 12 - No. 23 • 2019 • Enero - Junio · Corporación Universitaria Americana • Barranquilla, Colombia • ISSN: $2027-2448$. 
garante dentro de los garantes de cuidado se desprende las estrechas relaciones de comunidad, en tanto motiven la dependencia de uno de los partícipes en las mismas respecto a otros. Son ejemplos las comunidades de riesgos en las peligrosas excursiones de montañas... y expediciones, las familias de hecho, sin matrimonio formal de los padres, y la admisión en el hogar propio de personas necesitadas de cuidado. Y el tercer grupo de posiciones de protección, proviene de la asunción voluntaria de un deber de cuidado frente a personas en peligro o frente a un tercero en provecho de aquél. Constituyen ejemplos de ello el médico respecto a sus pacientes... o el guía de montaña frente al turista que conduce...

El segundo grupo de las posiciones de garante se caracteriza atendiendo la responsabilidad por seguridad contra determinados peligros que proceden del propio círculo de la vida del autor por omisión (garantes de seguridad). El ámbito de los deberes de garante es en este grupo distinto y más estrecho que en el primero, porque aquí el garante sólo tiene que mantener bajo control la propia fuente de peligro.

Por de pronto [sic] se incluye en este grupo el deber de garante que se deriva del previo hacer peligroso. Aquel descansa en la idea básica de que cada uno ha de responder de que [sic] un evidente riesgo producido por el mismo, no desemboque en un resultado típico...

Un deber de garante se desprende también de fuentes de peligro que se sitúan o nacen dentro del área de dominio privado. Aquí cuentan en primer lugar, los importantes deberes relativos a la seguridad de la circulación viaria. Y el deber de vigilar la seguridad en el tráfico de vehículos de motor. Un último subcaso del segundo grupo de las posiciones de garantes proviene de que [sic] alguien tenga la responsabilidad por la actuación de terceras personas. Así particularmente los encargados de la educación tienen que preocuparse de que los menores de edad confiados a su control no comentan ningún delito" (Jescheck, 1993, p. 19).

De manera que las fuentes materiales de la posición de garante, también conocidas como fuentes funcionales ubica su punto de vista en las relaciones fácticas entre las partes mediante el ejercicio de roles sociales particulares. Como ya se expresó se fundamenta en el criterio que señala que en la sociedad cada individuo cumple y tiene asignado roles o funciones específicas y por tanto se encuentra obligado, como se señaló a cumplirlas, precisamente por las expectativas sociales que generan en el conglomerado social.

\section{Conclusiones}

De conformidad con lo reseñado en este artículo reflexivo de investigación, debe rescatarse que la doctrina ha planteado, entre otros, que el deber de tutela y custodia de determinados bienes jurídicos abarca:

Por un lado, estrechas vinculaciones materiales; estrictas relaciones comunitarias; posición de garante de órganos representativos; la asunción voluntaria de una función protectora y la asunción unilateral de una función de vigilancia. Por otro lado, el deber de aseguramiento de una fuente de riesgo comprende a su vez, el control sobre una fuente de peligro ubicada en la esfera personal de dominio y el control de la actuación peligrosa de terceros.

En este orden de ideas y a pesar de los avances dogmáticos que sobre la materia se han producido, como también de las diversas tendencias teóricas que sobre el tema existen, llama profundamente la atención el estado de cosas que sobre tan importante temática se da en estas latitudes. 
Por todo lo anterior, es del caso destacar que la mayoría de los comportamientos punibles de comisión por omisión de algunos servidores públicos de Colombia generan reacciones mediáticas y coyunturales, tales como ha sucedido con las centenares de muertes de niños de la etnia Wayuu por hambre física, los treinta y tres niños incinerados en la ciudad de Fundación y las numerosas muertes de personas ocasionadas por los denominados "arroyos" de la ciudad de Barranquilla, entre otros.

Todo esto evidencia nuestra realidad frente a la inoperancia de la Posición de Garantía Institucional de los Agentes que representan al Estado, lo que se refleja en el poco o a veces inadecuado manejo que desde el campo de la Administración de Justicia se le ha dado a la citada figura; situación que desde luego ha impactado en su escaso desarrollo dogmático y jurisprudencial si se le compara con las de otras latitudes; especialmente, con las de Alemania o España, por ejemplo.

De tal manera que las regulaciones jurídicas por sí solas no pueden resolver los problemas que al respecto vive Colombia. Si bien es cierto ellas existen, también lo es, que su efectividad no es coherente con el contexto de aplicación de las mismas, particularmente en el ámbito penal donde toca todos los niveles, pero donde más campea es en la judicialización por la posible responsabilidad de los Agentes del Estado por comportamientos punibles de comisión por omisión.

Alrededor de lo expresado se añadirá, que si bien es cierto, el desarrollo teórico permite la resolución de los casos prácticos, también lo es, que dichos avances de nada valen, sino tienen una aplicación práctica y más aún en materia penal, para poder darles una solución razonable y justa pero sin olvidar que su legitimación y fundamentación se encuentra en la sociedad donde se aplican. En otras palabras, que se engarcen los problemas sociales con la normatividad jurídica, su interpretación y efectiva aplicación.

En consecuencia, se inferirá que las normas jurídicas por sí solas no pueden resolver los problemas concretos que al respecto vive Colombia. Existen las regulaciones jurídicas pero su efectividad no es coherente con el contexto de aplicación de las mismas. 


\section{Referencias}

Congreso de Colombia. (5 de febrero de 200). Código Disciplinario Único. [Ley 734 de 2002]. DO: 44.708.

Forero Ramírez, J. C. (2005). El delito de omisión en el nuevo código penal. Bogotá, Colombia: Legis.

Jakobs, G. (2000). Acción y omisión en el Derecho Penal. Cuadernos de conferencias y artículos. Bogotá, Colombia: Universidad Externado de Colombia.

Jescheck Hans, H. (1993). Problemas del delito impropio de omisión desde la perspectiva del Derecho Comparado. Nuevo Foro Penal, 9-23.

Jiménez García, F. (2011). La responsabilidad directa por omisión del estado más allá de la diligencia debida. Reflexiones a raíz de los crímenes «feminicidas» de ciudad Juárez. Revista Española de Derecho Internacional. LXIII (2). 11-50.

Kaufmann, A. (1980). Dogmática de los Delitos de Omisión. Madrid, España: Marcial Pons.

Novoa Monreal, E. (1984). Fundamentos de los delitos de omisión. Buenos Aires, Argentina: Depalma.

Roxin, C. (1972). Política Criminal y Sistema del Derecho Penal. Barcelona, España: Urgel.

Terragni, M. (2010). Posición de Garante y Derechos Fundamentales. En C. I. Jaramillo, Realidades y Tendencias del Derecho en el Siglo XXI (359-383). Bogotá, Colombia: Temis.

Zaczyk, R. (2010). Sobre la posición de garante de los funcionarios. Libertad, derecho y fundamentación de la pena. Bogotá, Colombia: Universidad Externado de Colombia. 